\title{
Determination of Melamine in Infant Milk Formula, Milk Powder and Basaa Fish Samples by HPLC/DAD
}

\author{
Mohamed M. Deabes ${ }^{1 *}$ and Roquaia El- Habib ${ }^{2}$
}

${ }^{1}$ Food Toxicology and Contaminants Department, National Research Centre, 33-El Bohouth street-Dokki, Cairo, Giza 12311, Egypt ${ }^{2}$ Biology Department, College of Arts and Science, Qassim University, Kingdom of Saudi Arabia

\begin{abstract}
Thirty two samples were collected of milk powder for baby and human consumption and Basaa fish 8 infant milk formula, 8 growing up milk formula purchased from pharmacy in Saudi Arabia, 6 Sweetened Full Cream Milk Powder purchased from China and 10 fish samples (Basaa fish) Ui Tnam purchased from popular markets in Saudi Arabia. The samples were analyzed and determination for Melamine (MEL) by HPLC/DAD. The incidence of MEL in powder milk and in fish, was about 100 and $80 \%$ respectively. High concentrations were found in growing up milk formula. Melamine was detected in 28 out of 32 samples with varying concentrations. Of the 28 melamine positive samples, samples had a melamine concentration higher than $258 \mathrm{mg} / \mathrm{kg}$ (the median). The lowest and the highest concentrations were found to be 7.5 and $258 \mathrm{mg} / \mathrm{kg}$, respectively in all samples. This application note describes an efficient and simple method for preparing milk powder and fish samples coupled to an HPLC/DAD method for rapid analysis of melamine in these samples. The purpose of the survey was to determine levels of melamine and to monitor the effectiveness of the controls in place to limit consumer exposure to melamine.
\end{abstract}

Keywords: Exposure; Melamine; Infant milk formula; Powder milk; HPLC; Bassa fish

\section{Introduction}

Melamine (2,4,6-triamino-1,3,5-triazine) is used in the production of plastics, in finishers for paper, in fertilizer, as a flame retardant, and in the manufacture of wrinkle-free textiles Garber [1]. The use of melamine as a nonprotein nitrogen source for cattle was studied by Newton and Utley [2]. Although the melamine was digested, most of the nitrogen was eliminated in the urine and not assimilated by microbes in the rumen. Since the spring of 2008, an increase of urinary tract stones in infants and young children were noticed by pediatricians in Gansu, Hebei, Beijing, and other cities/provinces. This was followed by an epidemic of urinary tract stones in infants and young children in more than 10 provinces in the mainland of China. In September 2008, the cause of this unusual epidemic was identified, i.e. the illegal use of "protein essence" (melamine, an industrially synthesized chemical) in raw milk (the main ingredient of infant formula) to falsely increase the protein content of raw milk after dilution with water. This was a typical case of raw milk adulteration. When melamine concentration was high enough in the infant formula, because of its very low solubility, it formed crystals or stones in the urinary tract of infants and young children [3]. Melamine is classified by the World Health Organization as not posing a health risk [4]. The use of melamine-formaldehyde resins in the production of molded plastics and as coatings in contact with food is approved by the U.S. Food and Drug Administration (FDA) as long as the yield of chloroform-soluble extractives does not exceed $0.5 \mathrm{mg} / \mathrm{in}^{2}$ of food contact surface [5].

Since melamine is a raw material in the production of some plastic products used for serving food, low-level migration of melamine into the food has been reported. Thus, melamine was detected using liquid chromatography in beverages at levels of $0.54,0.72,1.42$ and $2.2 \mathrm{mg} /$ $\mathrm{kg}$ in coffee, orange juice, fermented milk and lemon juice respectively, with a limit of detection of $0.05 \mathrm{mg} / \mathrm{L}$ [6]. These levels originated from migration of melamine from the cup, made of melamine-formaldehyde resin, into the beverage under experimental hot and acidic conditions $\left(95^{\circ} \mathrm{C}\right.$ for $\left.30 \mathrm{~min}\right)$ [7].

Much higher levels of melamine have been detected in food, feed or raw materials following fraudulent practices: data reported in 2007 by the U.S. FDA [8] showed melamine in wheat gluten and rice protein concentrate imported from China at levels in the range of 2 to $80 \mathrm{mg} /$ $\mathrm{kg}$, with a limit of detection of $0.05-0.1 \mathrm{mg} / \mathrm{kg}$. Analyses of actual feed product showed melamine in fish feed samples ranging from 53 to $400 \mathrm{mg} / \mathrm{kg}$, respectively [8]. The U.S. Food and Drug Administration (FDA) derived a TDI for melamine of $0.63 \mathrm{mg} / \mathrm{kg}$ b.w. [8]. For adults, melamine is only dangerous in very high concentrations. In this regard, the US Food and Drug Administration (FDA) have set a tolerable daily intake (TDI) of $0.5 \mathrm{mg} / \mathrm{kg}$ body weight [8]. Since the spring of 2008 , an increasing number of kidney stones in infants were noticed by pediatricians in Gansu, Hebei, Beijing, and other cities/provinces in China [9].

The aim of the work is to perform an easy, fast, accurate and reliable analytical methodology to quantify the level of melamine in milk and fish. Also study on the occurrence of melamine in milk powder, infant milk formula and Bassa fish from Saudi Arabia and China.

\section{Materials and Methods}

\section{Sampling}

A total of 32 samples, Sweetened Full Cream Milk Powder (6 samples) for a whole family (in convenient pack) from China in Zahnghou, Fujan province, Xiamen and Hangzhou, Zhejiang Province were collected from markets While, infant milk formula (8 samples), growing up milk formula (8 samples) and Bassa fish (Ui Tnam) (10

*Corresponding author: Mohamed M. Deabes, Food Toxicology and Contaminants Department, National Research Centre, 33-El Bohouth streetDokki, Cairo, Giza 12311, Egypt, E-mail: mydeabes@yahoo.com

Received January 31, 2012; Accepted April 25, 2012; Published April 27, 2012

Citation: Deabes MM, El- Habib R (2012) Determination of Melamine in Infant Milk Formula, Milk Powder and Basaa Fish Samples by HPLC/DAD. J Environ Anal Toxicol 2:137. doi:10.4172/2161-0525.1000137

Copyright: (c) 2012 Deabes MM, et al. This is an open-access article distributed under the terms of the Creative Commons Attribution License, which permits unrestricted use, distribution, and reproduction in any medium, provided the original author and source are credited. 
samples) were randomly collected from Saudi Arabia, Qassim region (Byraida,Onyza, Al-Ras, Al-Badya and Al-Bokhria) .

\section{Reagents and chemicals}

Melamine standard (95\% purity) was purchased from Sigma (St. Louis, MO, USA). Water was obtained by distillation through a MilliQ water purification system (Millipore Ltd., Bedford, MA, USA). HPLCgrade methanol $(\mathrm{MeOH}), \mathrm{HPLC}$-grade acetonitrile $(\mathrm{ACN})$, reagentgrade formic acid (content 98-100\%) and HPLC-grade potassium dihydrogen phosphate (93\%) were purchased from Merck Germany).

Stock solution: $10.00 \mathrm{mg}$ of melamine (MEL) was added to a diluted to mark with a solution of $2 \%$ ammonium hydroxide in water (v/v) $100 \mathrm{~mL}$ volumetric flask and adjusted concentration to produce a stock solution $100 \mu \mathrm{g} / \mathrm{mL}$. The solution was sonicated for $20-30$ minutes until crystals of melamine were no longer visible.

Intermediate solutions: A $10.0 \mu \mathrm{g} / \mathrm{mL}$ standard was prepared by adding a $1.0 \mathrm{~mL}$ aliquot of the MEL stock to a $10.0 \mathrm{~mL}$ volumetric flask and diluting to the mark with water. A $1.0 \mu \mathrm{g} / \mathrm{mL}$ standard was prepared by adding a $1.0 \mathrm{~mL}$ aliquot of the MEL stock to a $100.0 \mathrm{~mL}$ volumetric flask and diluting to the mark with water.

\section{Extraction of melamine from:}

Milk powder: Five gram of baby infant or powder milk samples was transferred to $50 \mathrm{ml}$ volumetric flask, then $20 \mathrm{ml}$ methanol grade HPLC was added and mixed well by vortex. The mixture was sonicated for $10 \mathrm{~min}$. and then centrifuged at $4500 \mathrm{rpm} 10 \mathrm{~min}$. The extracts were evaporated to dryness by a gentle nitrogen stream. Afterwards, an aliquot of the supernatant was diluted with HPLC-grade methanol - water (8:2) according to FDA [10].

Fish: The extraction of melamine in fish was done according to the procedures of Wendy et al. [11]. Homogenized bassa fish tissue (5.0 g) was weighed into a $50 \mathrm{~mL}$ polypropylene centrifuge tube. To this was added $24 \mathrm{~mL}$ of a 50:50 (v:v) solution of acetonitrile: water and $1 \mathrm{~mL}$ of $1.0 \mathrm{~N}$ hydrochloric acid. The sample was capped, shaken vigorously for 30 seconds and then vortex mixed for 1 minute. The sample was centrifuged at $4000 \mathrm{rpm}$ for 5 minutes at $5^{\circ} \mathrm{C}$. Breaking through the solid fat layer at the top of the sample with the tip of a pipette, a 5 $\mathrm{mL}$ aliquot of supernatant was removed to a $15 \mathrm{~mL}$ polypropylene centrifuge tube. The remaining portion in the $50 \mathrm{~mL}$ tube was discarded. Dichloromethane $(10 \mathrm{~mL})$ was added to the contents of the $15 \mathrm{~mL}$ tube, and the sample was shaken for two minutes. The sample was centrifuged at $4000 \mathrm{rpm}$ for 5 minutes at $5^{\circ} \mathrm{C}$. A portion $(2.5 \mathrm{~mL})$ of the upper aqueous layer was carefully removed to a glass culture tube. Water $(2.5 \mathrm{~mL})$ was added to the dichloromethane layer and that sample was re-extracted by shaking for 1 minute. The polypropylene tube was again centrifuged at $4000 \mathrm{rpm}$ for 5 minutes at $5^{\circ} \mathrm{C}$, and the entire upper aqueous layer was removed and combined with the first aqueous extract in the glass culture tube. This extract was vortex mixed for 5 seconds. The SPE cartridge was conditioned with $5 \mathrm{~mL}$ of methanol followed by $5 \mathrm{~mL}$ of water. The sample was applied to the conditioned cartridge and allowed to elute by gravity. The column was washed with $5 \mathrm{~mL}$ of $0.1 \mathrm{~N} \mathrm{HCl}$, followed by $2 \mathrm{~mL}$ of methanol. The cartridge was dried by applying vacuum for 1 minute. The column was eluted into a glass culture tube using $5 \mathrm{~mL}$ of $5 \%$ ammonium hydroxide in methanol. The elute was evaporated to dryness at $55^{\circ} \mathrm{C}$ under flowing nitrogen at 15 psi for 20 minutes.

\section{Equipment and chromatographic conditions}

High-performance liquid chromatography (Agilent 1100 series) equipped with a photodiode array DAD (G 1315 B) analysis was carried out with a liquid chromatograph equipped with solvent delivery systems (Agilent Technologies, Inc.200 Regency Forest Drive, Suite 330 Cary, NC 27511 USA) system containing a G1322A Vacuum Degasser, a G1312A Binary and a reverse-phase analytical column packed with C18 material (Agilent ZORBA, X DB- $5 \mu \mathrm{m}, 150 \mathrm{~mm}$ $\times 4.6 \mathrm{~mm}$ ). The mobile phase consisted of methanol: water $(80: 20)$. Separation was performed at ambient temperature at a flow rate of 1.0 $\mathrm{ml} \mathrm{min}{ }^{-1}$; the injection volume was $50 \mu \mathrm{l}$ for both standard solutions and sample extracts by auto sampler (G1329A). The Dad detector was operated at a $220 \mathrm{~nm}$

\section{Results and Discussion}

The occurrence of melamine in infant milk formula, growing up milk formula and Bassa fish collected from different regions of Qassim, Saudi Arabia and Sweetened Full Cream Milk Powder from China is listed in Table 1 and Figure 1. Melamine was detected in 28 out of 32 samples with varying concentrations. Of the 28 melamine positive samples, concentration was $258 \mathrm{mg} / \mathrm{kg}$ (the mean value). The lowest and the highest concentrations were found to be 7.5 and $258 \mathrm{mg} /$ $\mathrm{kg}$, respectively. Figure (1a, $1 \mathrm{~b}$ and $1 \mathrm{c}$ ) showed the results obtained, depicts the chromatogram for melamine extraction from samples and HPLC analysis. As can be seen, possible interferences from substances present in samples were not observed. In addition, a detection and identification process based on retention times and a Diode-Array Detector (DAD) was carried out.

The percentage of positive samples with detectable levels of melamine was $100 \%$ in infant milk formula, growing up milk formula

\begin{tabular}{|l|l|l|l|l|}
\hline \multirow{2}{*}{ No of samples } & \multicolumn{4}{|c|}{ Mean of melamine concentration (mg/kg \pm SD) } \\
\cline { 2 - 5 } & Infant milk formula Mean \pm SD & Growing up milk formula Mean \pm SD & Basaa fish Mean \pm SD & Full Cream Milk Powder Mean \pm SD \\
\hline 1 & $9.49 \pm 0.35^{\text {a }}$ & $251.23 \pm 0.78$ & $7.5 \pm 0.28$ & ND \\
\hline 2 & $11.0 \pm 1.0$ & $61.4 \pm 0.78$ & ND & $39.8 \pm 0.44$ \\
\hline 3 & $13.0 \pm 1.15$ & $28.5 \pm 0.86$ & $12.26 \pm 0.14$ & $33.5 \pm 0.28$ \\
\hline 4 & $258 \pm 1.15$ & $5.97 \pm 0.04$ & $14.8 \pm 0.44$ & $35.4 \pm 0.30$ \\
\hline 5 & $252.0 \pm 1.45$ & $7.75 \pm 0.75$ & $13.5 \pm 0.28$ & $29.1 \pm 0.58$ \\
\hline 6 & $254.0 \pm 0.57$ & $31.66 \pm 0.88$ & $16.6 \pm 0.30$ \\
\hline 7 & $185.25 \pm 0.25$ & $200.0 \pm 0.57$ & Nd & - \\
\hline 8 & $192.7 \pm 1.45$ & $182.33 \pm 1.45$ & Nd & - \\
\hline 9 & - & - & $9.6 \pm 0.30$ \\
\hline 10 & - & - & & - \\
\hline
\end{tabular}

${ }^{\text {a }}$ Mean \pm S.D. for triplicate determinations

Table 1: Melamine concentrations in Infant milk formula, growing up milk formula, full cream milk powder and Basaa fish. 

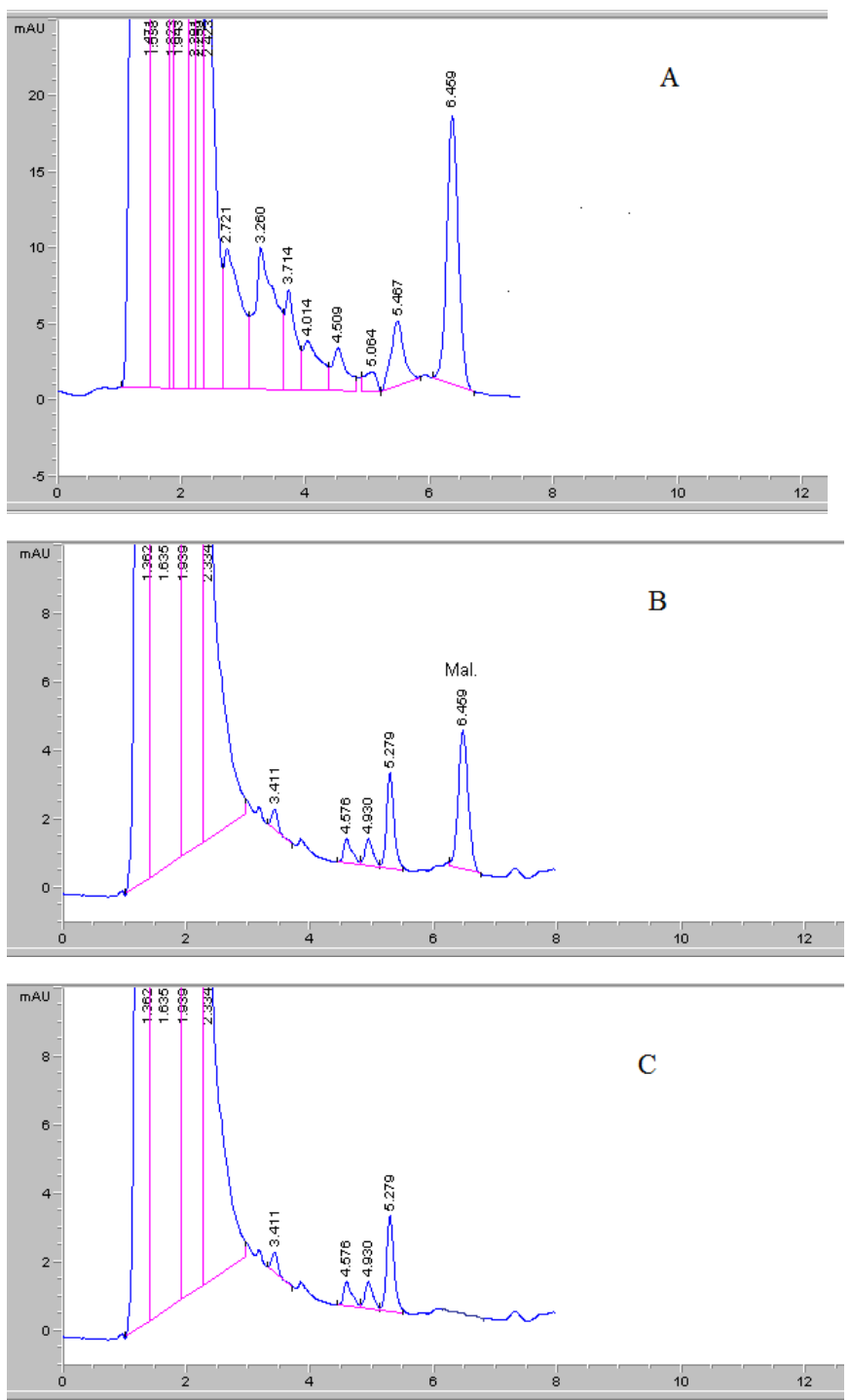

Figure 1: HPLC Chromatograms of melamine separation (A) standard, (B) positive sample and $(C)$ negative sample.

from Saudi Arabia and full cream milk powder from China, while in Bassa fish $60 \%$. The percentage of melamine contamination was high different between the raw material fish and milk powder may be in China, where adulteration had occurred, water had been added into raw milk to increase the volume. As a result of this dilution, the milk had a lower protein concentration and the companies using the milk for further production (e.g. of powdered infant formula) would produce the products which had a low protein content but high melamine. Recently, an increased incidence of kidney stones and renal failure in infants was reported in China which was believed to be associated with the ingestion of infant milk-based formula contaminated with melamine [12]. It seemed that again nitrogen-rich melamine was added to raw milk to boost its apparent protein content.

Human could be also exposure to melamine and its analogues from a number of other sources. Firstly, one of the sources would be from breakdown of the pesticide cyromazine, which is approved for use in many countries [13]. Secondly, migration from melamine resin containers to food has been reported [7]. Thirdly, melamine could be introduced into human diets as it may carry over from the illegal use of melamine in animal feed or feed ingredients although no quantitative data exist. In this regard, some data have shown that the carry-over occurs from feed to products of animal origin including milk, eggs, meat, and fish. Lastly, contamination of melamine into the food chain as a baseline level is possible as it is present in the environment and the widespread use of melamine-containing materials [14].

The results presented in Table 2 shows that melamine was detected at levels greater than $1 \mathrm{mg} / \mathrm{kg}$ compared with the control limit set in China in powdered infant formula $(1 \mathrm{mg} / \mathrm{kg})$ and in other foods $(2.5$ $\mathrm{mg} / \mathrm{kg}$ ). The US Food and Drug Administration (FDA) sets $2.5 \mathrm{mg} /$ $\mathrm{kg}$ as the concern level, while Hong Kong, China and New Zealand also set a safe limit in food products of $2.5 \mathrm{mg} / \mathrm{kg}$, though Hong Kong has lowered the level for children under 3 and pregnant or lactating women to $1 \mathrm{mg} / \mathrm{kg}$. Compared with $1 \mathrm{mg} / \mathrm{kg}$, the melamine contents of all samples in Table 1 exceeded the limit level notably. The baseline level refers to the amount of melamine from the unintentional use, while the adulteration level is that of melamine in food that result from the intentional addition of melamine or the unapproved use or misuse of melamine and any substances that can degrade to form melamine [14]. Maximum permitted concentration for melamine in food has been set at $2.5 \mathrm{mg} / \mathrm{kg}$ by the European Commission [15,16]. Hong Kong established tolerance at $1 \mathrm{mg} / \mathrm{kg}$ in infant foods and Taiwanese authorities stated that melamine should not be detected in any food using the most sensitive instrumentation [15].

The UV absorption of melamine is reported in wide range between 210 and $240 \mathrm{~nm}$, such as $214 \mathrm{~nm}$ [17], $215 \mathrm{~nm}$ [18], $220 \mathrm{~nm}$ [19], 236 $\mathrm{nm}$ [20], $240 \mathrm{~nm}$ [21], etc. The difference of detection wavelength maybe related to the polarity and cut-off wavelengths of the solvents used in the mobile phases. We compared the absorption of melamine in the mobile phase solution within the range of 205-240 nm, and found that the absorption decreased markedly with the increased wavelength. Considering the cut-off wavelength at $220 \mathrm{~nm}$ was thus selected for detection of melamine.

The present results showed that the Infant milk formula samples had an unacceptable level of melamine. Furthermore, the high level of melamine was found in the infant milk formula followed by milk formula from the collected samples in Saudi Arabia.

Melamine was detected using liquid chromatography in beverages at levels of $0.54,0.72,1.42$ and $2.2 \mathrm{mg} / \mathrm{kg}$ in coffee, orange juice, fermented milk and lemon juice respectively, with a limit of detection of $0.05 \mathrm{mg} / \mathrm{L}$ [6]. These levels originated from migration of melamine from the cup, made of melamine-formaldehyde resin, into the beverage under experimental hot and acidic conditions $\left(95^{\circ} \mathrm{C}\right.$ for $\left.30 \mathrm{~min}\right)$ [7]. Much higher levels of melamine have been detected in food, feed or raw materials following fraudulent practices: data reported in 2007 by the U.S. FDA [8] showed melamine in wheat gluten and rice protein concentrate imported from China at levels in the range of 2 to $80 \mathrm{mg} /$ $\mathrm{kg}$, with a limit of detection of $0.05-0.1 \mathrm{mg} / \mathrm{kg}$. Analyses of actual feed

\begin{tabular}{|l|l|l|l|l|l|}
\hline Samples & $\begin{array}{l}\text { No of } \\
\text { samples }\end{array}$ & $\begin{array}{l}\text { \% of positive } \\
\text { samples }\end{array}$ & $\begin{array}{l}\text { Mean } \\
(\mathrm{mg} / \mathrm{kg})\end{array}$ & $\begin{array}{l}\text { Minimum } \\
(\mathrm{mg} / \mathrm{kg})\end{array}$ & $\begin{array}{l}\text { Maximum } \\
(\mathrm{mg} / \mathrm{kg})\end{array}$ \\
\hline Infant milk formula & 8 & 100 & 146.93 & 9.49 & 258 \\
\hline Growing up milk formula & 8 & 100 & 96.105 & 7.75 & 251 \\
\hline Basaa fish & 10 & 60 & 12.73 & 9.6 & 16.6 \\
\hline $\begin{array}{l}\text { Full Cream Milk Powder } \\
\text { from China }\end{array}$ & 6 & 100 & 34.18 & 29.1 & 39.7 \\
\hline
\end{tabular}

Table 2: Detection of Melamine in Infant milk Formula, Growing up milk formula Full Cream Milk Powder and Bassa fish Samples $(n=3)$. 
product showed melamine in fish feed samples ranging from 53 to $400 \mathrm{mg} / \mathrm{kg}$, respectively [8]. The U.S. Food and Drug Administration (FDA) derived a TDI for melamine of $0.63 \mathrm{mg} / \mathrm{kg}$ b.w. [8]. In recent study by Li et al. [22] found an increasing risk of nephrolithiasis with increasing levels of daily melamine intake, starting at a lower intake than $0.2 \mathrm{mg} / \mathrm{kg}$ of body weight. This result holds true after adjustment for exposure time, preterm, urinary, malformation, and parents with a history of urinary stones. The TDI for melamine of $0.2 \mathrm{mg} / \mathrm{kg}$ of body weight as recommended by the WHO seems to be too high for young children. It should at least be lower than $0.1 \mathrm{mg} / \mathrm{kg}$. In today's world, it is crucial to understand and deal with the global implications of food borne diseases if problems like the melamine epidemic are to be prevented.

\section{Conclusion}

The present results showed that the Infant milk formula samples had an unacceptable level of melamine. Furthermore, the high level of melamine was found in the infant milk formula followed by milk formula from the collected samples in Saudi Arabia. This application note describes an efficient and simple method for preparing milk powder and fish samples coupled to an HPLC/DAD method for rapid analysis of melamine in these samples. As can be seen, possible interferences from substances present in samples were not observed. In addition, a detection and identification process based on retention times and a diode-array detector (DAD) was carried out.

\section{References}

1. Garber EA (2008) Detection of Melamine Using Commercial Enzyme-Linked Immunosorbent Assay Technology. J Food Prot 71: 590-594.

2. Newton GL, Utley PR (1978) Melamine as a dietary nitrogen source for ruminants. J Anim Sci 47:1338-1344.

3. WHO (1986) World Health Organization, International Agency for Research on Cancer. Melamine, p. 333-346. In IARC monographs on the evaluation of the carcinogenic risk of chemicals to humans: some chemicals used in plastics and elastomers, vol 39 International Agency for Research on Cancer, Lyon, France.

4. Ingelfinger JR (2008)Melamine and the Global Implications of Food Contamination. N Engl J Med 359:2745-2748.

5. Ishiwata $\mathrm{H}$, Inoue T, Tanimura A (1986) Migration of melamine and formaldehyde from tableware made of melamine resin. Food Addit Contam 3: 63-69.

6. Ishiwata H, Inoue T, Yamazaki T, Yoshihira K (1987) Liquid chromatographic determination of melamine in beverages. J Assoc Off Anal Chem 70: 457-460.

7. FDA (2007) U.S. Food and Drug Administration, Center for Food Safety and Applied Nutrition. Pet food recall (melamine)/tainted animal feed. July 23, 2007.
8. Zhang L, Wu LL, Wang YP, Liu AM, Zou CC, et al. (2009) Melaminecontaminated milk products induced urinary tract calculi in children. World $J$ Pediatr 5: 31-35.

9. FDA (2008) Decent HPLC Assay Method for Melamine (From FDA: Melamine found in baby formula made in China.) Chemistry Loves Chemistry Decent HPLC Assay Method for Melamine.mht. Thursday, September 18, 2008.

10. Wendy C, Sherri BAT, Karbiwnyk CM, Madson MR (2007) Determination of Melamine Residues in Catfish Tissue by Triple Quadrupole LC-MS-MS with HILIC Chromatography. U.S. Food and Drug Administration Laboratory Information. 23: 4396.

11. SAC (2008) Determination of Melamine in Raw Milk and Dairy Products. SAC Standards GB/T 22388-2008. Standardization Administration of the People's Republic of China (SAC), Beijing, P.R. China.

12. Sancho JV, Ibanez M, Grimalt S, Pozo OJ, Hernandez F (2005) Residue determination of cyromazine and its metabolite melamine in chard samples by ion-pair liquid chromatography coupled to electrospray tandem mass spectrometry. Anal Chim Acta 530: 237-243.

13. WHO (2008) Expert meeting to review toxicological aspects of melamine and cyanuric acid, Ottawa, Cananda, 1-4 December 8, 2008, Executive Summary.

14. Shia J, Mallet C, Young M, Li J, Meng Y, et al. (2008) Application Note 72000282EN.Rapid, specific analysis of melamine contamination in infant formula and liquid milk by UPLC-MS/MS, Waters Corporation .

15. EC (2008) European Commission Decision 2008/798/EC, imposing special conditions governing the import of products containing milk or milk products originating in or consigned from China, and repealing Commission Decision 2008/757/EC.

16. Yokley RA, Mayer LC, Rezaaiyan R, Manuli ME, Cheung MW (2000) Analytical method for the determination of cyromazine and melamine residues in soil using LC-UV and GC-MSD. J Agric Food Chem 48: 3352-3358.

17. Pukkila J, Peltonen K, Savolainen T (1987) Determination of melamine in air by high-performance liquid chromatography with ultraviolet detection. J Chromatogr 411, 409-414.

18. Muniz-Valencia R, Ceballos-Magaña SG, Rosales-Martinez D, GonzaloLumbreras R, Santos-Montes A, et al. (2008) Method development and validation for melamine and its derivatives in rice concentrates by liquid chromatography. Application to animal feed samples. Anal Bioanal Chem 392:523-531.

19. He Q, Liu M, Huang L, Yang Y, Liao S (2008) Determination of melamine in milk powder and milk by high performance liquid chromatography. Se Pu 26 752-754.

20. China, Standardization, Administration of PRC (2008) Rapid determination of melamine in raw milk: High performance liquid chromatography method. GB/T 22400-2008. Beijing.

21. Li G, Jiao S, Yin X, Deng Y, Pang X, et al. (2010) The risk of melamineinduced nephrolithiasis in young children starts at a lower intake level than recommended by the WHO. Pediatr Nephrol 25:135-141. 